\title{
Cross-Linguistic Influence On The Acquisition Of English Pronunciation By Tunisian EFL Learners
}

\author{
Nadia Bouchhioua, PhD \\ Faculté des Lettres, des Arts et des Humanités, \\ Université de La Manouba, Tunisia
}

doi: 10.19044/esj.2016.v12n5p260 URL:http://dx.doi.org/10.19044/esj.2016.v12n5p260

\begin{abstract}
While acquiring English as a second language (L2) has received substantial research, learning English as a third language (L3) especially in complex sociolinguistic contexts has not received as much attention. Various factors including typological similarity between L2 and L3 are believed to affect the process and the product of learning a third language. Typological similarity is said to facilitate learning at the lexcio-semantic level. However, its effects on the learning of L3 phonology is not always as such. In this study, cross-linguistic influence on the acquisition of English (as L3) pronunciation in the Tunisian context which is characterized by multilingualism involving Tunisian Arabic (TA) as mother tongue, Modern Standard Arabic (MSA) as the first language learnt at school, and French as L2 is investigated. The production of two pronunciation features is tested. These features are the sounds $\mathbf{i n}, \boldsymbol{y n}, \mathbf{i m}>$ existing in English-French cognates such as information, syntax, important, and stress placement in polysyllabic words. The methodology consisted in having English major university students and their teachers produce these features in read and spontaneous speech. Phonetic analysis and statistical tests revealed significant linguistic transfer from French in the pronunciation of the target features. The participants produced the French nasalized vowel $[\tilde{\varepsilon}]$ in the syllables $\boldsymbol{i n}, \boldsymbol{y n}, \mathbf{i m}>$ in English-French cognate vocabulary instead of the correct English pronunciation and placed stress on final syllables according to French stress patterns in their production of English polysyllabic words that should be stressed elsewhere.
\end{abstract}

Keywords: Third language acquisition, pronunciation, interference, French, English, Tunisian Arabic 


\section{Introduction}

Cross-linguistic influence in the process of second language (L2) acquisition has for long been an essential topic in second language acquisition research. Most of the research conducted, however, was generally limited to examining the effects of the learner's mother tongue on the acquisition of the target language. Learning a foreign language in a third position, that is, after a second language has been acquired has not received as much interest and remained a relatively under-investigated field. Various factors such as such typological similarity between languages (Andersen, 1983; Kellerman, 1983,1995) and the speaker's level of proficiency (Kellerman, 1983; Odlin, 1989) seem to affect the learning of a third language (L3). In fact, when the learner's level of proficiency in L3 is low and when a typological similarity between the L2 and L3 exists, transfer from the L2 features to the L3 is likely to occur.

Oldin (1989, p. 27) defines transfer as "the influence resulting from similarities and differences between the target language and any other language that has been previously (and perhaps imperfectly) acquired.” This influence arises from the learner's conscious or unconscious judgment that something in the native language and something in the target language are similar if not the same. These similarities lead to interference which is also referred to in the literature as negative transfer. Negative transfer is often related to difficulties in learning and is always opposed to positive transfer which is defined by Oldin (1989, p.26) as "the facilitating influence of cognate vocabulary or any other similarities between the native language and the target language." Kellerman (1979) argues that transfer should be considered as a cognitive process in which decisions are made on the basis of the learner's perception of the similarity between first and second language structures and the degree of markedness of this language structure. Transfer is predicted to occur when the perceived similarity between the two languages is great and when the structures involved are unmarked.

Other researchers such as Sharwood Smith and Kellerman (1986), however, find that the term transfer is not appropriate to cover the full range of language contact effects and prefer to limit the notion of transfer to "those processes that lead to incorporation of elements from one language to another" (p.1). They consider the term cross-linguistic influence more suitable to refer to other language contact phenomena such as L2/L1 transfer, language loss, or avoidance. Both terms 'transfer' and 'cross-linguistic influence', yet, encompass the effects that a previously learnt language may have on the learning of the following language. In fact, while learning L3, learners often inadvertently produce inter-language forms that consist of partially or totally L2 forms either at the lexical, morphological, or phonological level (Murphy, 2003). Tunisian learners of English make no 
exception especially that the socio- linguistic context in which they live and learn new languages is a complex one.

The present study therefore attempts to investigate the effects that French, as the L2 acquired by Tunisian students (whose mother tongue is Tunisian Arabic), has on their acquisition of English pronunciation (as L3).

\section{Literature review}

\section{Acquiring English as a third language in the Tunisian educational context}

The linguistic situation in Tunisia is a complex one since this society is characterized by Diaglossia. Like in any other Arab country, in Tunisia, people speak Tunisian Arabic (the local dialect or variety) as their mother tongue. This language is used for social interaction but does not have an official state. Modern standard Arabic (MSA) is the official language of the country. It is the language used to teach reading and writing to children at school since the age of six. Most subjects (history, geography, math, etc...) at primary school are also taught in MSA. It is also the language used by public media for news broadcasting and for official announcements. French is then taught at basic school for children at the age of eight. At high school (secondary education), French acquires the status of a second language as most scientific subjects such as math, physics, chemistry, biology, technology and computer science are taught in French. It is also used in daily communication within society and most Tunisian have a regular tendency to switch codes between Arabic and French in their speech. English is only taught as a foreign language (EFL) in third position after Modern Standard Arabic (MSA) and French. The demand on learning English, in both public and private education, is yet growing rapidly because it is seen as the language of scientific and technological development and international communication. In this regard, it is overriding French and all other foreign languages.

Seen the typological similarity between French and English and because of the typological disparity of these two languages from Tunisian Arabic, transfer from French to English is often noticed at the lexical, grammatical and morphological level in the English productions of Tunisian EFL learners. Acquiring English as a third language is, actually, a more intricate experience than acquiring it as a second language because the process and product of acquiring a second language can influence the acquisition of a third one. Clyne (1997:113) states that "the additional language complicates the operations of the processes". Third language learners possess more familiarity and experience with learning languages than the second languages ones do, and their meta-linguistic awareness seems to be higher (Cenoz and Jessner, 2000) since they have already 
learned two other languages as first and second languages. According to Cenoz and Hoffmann (2003), the knowledge and the experience of the acquisition process of these two languages are likely to influence the acquisition of a third language either positively or negatively. In the Tunisian context, the acquisition of English as a third language is affected by the contextual and linguistic factors influencing this multilingual society. The linguistic typology and the socio-cultural status of the languages involved in this context (TA, MSA, and French) are believed to influence the development of learner's spoken and written production in English.

According to Cenoz (2001), speakers have the tendency to borrow more terms from the language that is typologically closer to the target language. Tunisian EFL learners would consequently benefit from their knowledge of French at the lexico-semantic level. The knowledge of French as L2 will facilitate their comprehension and processing of cognate vocabulary (English words that are similar in form to French) such as, restaurant, page, or hotel. Negadi (2015) reports positive effects of knowing French on the comprehension and the ability of translating English texts into French by Algerian EFL learners; a population which is very similar to the population of Tunisian EFL learners (Algerian Arabic as MT, French as L2, and English as L3). However, this knowledge can also negatively affect their acquisition and increase their errors such in Hanafi (2014) who reports errors made by Algerian learners of English as a third language with French as L2. These errors include orthographic interference errors where the spelling of some words is changed under the influence of French such as groupe spelled with additional "e" rather than "group", lexical interference errors like the word langues used instead of "languages", or fautes used instead of "mistakes", as well as grammatical interference errors occurring mainly in terms of word order such as image clear instead of "clear image", use of pronouns and determiners, as well as errors in tense and mood. These types of interference errors may be attributed to the learner's lack of proficiency in English since these learners seem to resort to French vocabulary items or word order to compensate for the existing gaps in their English proficiency. Such errors can be corrected with more instruction and more exposure to the language.

What seem to be more problematic are phonetic and phonological errors that derive from French-English interference. Research by Ghazali and Bouchhioua( 2003) showed that Tunisian EFL learners use the stress rules of their native language (TA) when they assign stress to Basic English words ( such as un'til, 'backward, up'set, incorrectly produced as 'until, back'ward, 'upset, respectively), but use French stress rules to assign stress to English French cognates such as ('passport, produced as pass'port...). The orthographic and semantic similarity between English-French cognates 
makes Tunisian EFL learners who have already acquired French before resort to French stress rules and provide wrong rendition of lexical stress. They would consequently confuse listeners and reduce their comprehensibility since French and English dispose of completely different phonological rules for word stress placement. In fact, producing the correct stress pattern is considered one of the most important factors for successful communication and intelligible speech (Derwing, Munro, \& Wiebe, 1998). Ghazali and Bouchhioua's (2003) study was, however, limited to exploring the effects of Tunisian Arabic on English words with a syllabic structure similar to the syllabic structure of TA words and to English-French cognates, which would trigger interference from the two previously learnt languages, respectively. Polysyllabic English words with no similarity to either French or TA syllable structures were not examined to see what would explain possible wrong stress placement in such words. In addition, their study was confined to examining the suprasegmental feature of lexical stress and did not check whether interference from French also occurs at the segmental (consonant or vowel) level.

Because of the importance of both English segments and suprasegmental features such as words stress for intelligibility and comprehensibility of L2 learners' speech, this research has chosen to explore the effects of French as L2 on the acquisition of English (as L3) pronunciation. The specific features explored are:

1) The production of the syllables $\langle\mathbf{i n}, \boldsymbol{y n}, \boldsymbol{i m}>$ in words like information, syntax, important, the spelling and meaning of which are similar to French.

2) Stress placement in English polysyllabic words the syllabic structure of which has no resemblance to either English-French cognates or TA stress patterns.

A brief overview of these two features and the way they are used in the languages concerned is provided in the next section.

\section{Nasalized vowels in French and English}

In addition to oral vowels, French has a handful of vowels that are nasalized: that is, when pronounced, the speaker deliberately lets the air escape through the nose and the mouth simultaneously. While oral vowels are produced within the oral cavity, nasal vowels in French are produced when the velum is lowered so that the air flow goes through the nose as well as the mouth. They are produced by vibrating the vocal cords and without any obstruction of the throat, tongue or lips. They can form syllables of their own. In writing, nasalized vowels are generally represented by one or more vowel letters followed by a letter $<\mathbf{n}>$ (or occasionally $<\mathbf{m}>$ ), and where this $<\mathbf{n}>$ is either at the end of a word or followed by another consonant. 


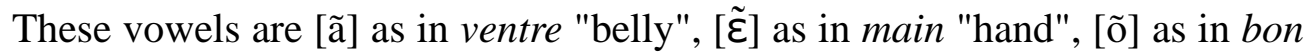

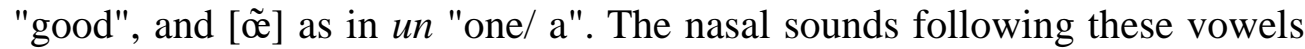
are not pronounced and totally assimilate into the vowel sound. In addition, nasal vowels in French are phonemic since words that differ mainly in the nasal or oral quality of a vowel exist. For example, the French words beau [bo] "beautiful" and bon [bõ] "good" differ only in that the vowel sound in the former is oral and in the latter is nasal.

English has nasalized vowels too which appear in words like sing or moon. However, the nasal sound following the vowel in English is

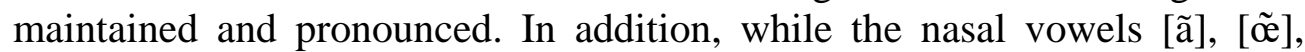
and[õ] are typically French and do not frequently appear in orthographic forms similar to English or in English-French cognates, the nasal vowel [ $\tilde{\varepsilon}]$ recurrently appears orthographically in English-French cognate vocabulary such as information, syntax, linguist. Tunisian EFL learners who have already acquired how to pronounce these nasalized vowels in French are expected to transfer this pronunciation into English, especially when the vowel appears in English-French cognates such as the word information, which has the same spelling and meaning in the two languages. They, thus, would produce the French pronunciation of the grapheme <in $>$ in the word information as $[\tilde{\varepsilon}]$ and consequently produce an incorrect version of the English syllable [ĩn]. Although such errors just reflect foreign accent and may not affect the intelligibility of the speaker, they do confuse the listener and make his task of getting the right message more difficult than it should be. Recognizing these errors and treating them properly in pronunciation classes would help the learner and enhance the comprehensibility of his/her speech.

\section{French and English stress patterns}

While listening to connected speech by native-speakers of French, one gets the impression of a regular succession of syllables uttered at a rather staccato and steady rate until a pause is reached. It is also noticed that the syllables occur with very little perceptible variation in rhythm. For this reason, French is usually described as a syllable-timed language since the basic rhythm is imposed by the syllable. In fact, when emotion or emphasis are not involved, every isolated word in French receives stress on the last syllable. For example, the words "maison" [mIzã] (House) or "chocolat "[ [okola] (chocolate) receive stress on the final syllable. French word stress is also described to be a weak one. Battye and Hintze (1992) assert that "not 
only are the syllables [of French words] of equal duration but none stands out as being more prominent than any other save for the final pronounced syllable before a pause" ( p.130). Thus, word stress in French is fixed according to this invariable rule, no matter how many syllables make up the word. This can be illustrated by the following examples:

'Pend

De'pend one syllable bearing the stress

Depen'dant 2 syllables with stress on the second (final) syllable

Independa'mment $\Rightarrow$ 3 syllables with stress on the third (final) syllable 5 syllables with stress on the final syllable

These stress rules of French are completely different from English word stress placement rules. Actually, English word stress is a non-fixed stress occurring at any syllable of the word (first syllable, anti-penultimate, penultimate or final syllable) but stable at the same time since the syllable that bears stress in a certain word is always the same. Tunisian EFL learners having already acquired the stress rules of French as L2 are faced by the new non-fixed and therefore more complex word stress patterns of English as L3 and are likely to suffer from cross-linguistic influence or 'negative transfer' in their assignment of stress to English words. The production of English word stress by Tunisian EFL learners has been investigated by Ghazali and Bouchhioua (2003) and the results show that this group of learners tend to apply the stress rules of their mother tongue (TA) when they assign stress to Basic English words such as "until","upset" and assign them initial stress while they should be stressed on the final syllables because they are subconsciously applying the stress rules of TA which says that " stress falls on the last syllable when it is long and on the penultimate in all other cases" ( Ghazali, 1973, p.73). A long syllable in TA is one which has the following syllable structure: a short vowel followed by two consonants, a short vowel followed by a long consonant, a long vowel followed by a short consonant, a long vowel followed by a word boundary (Ghazali, 1973). An English word like until would be considered to have a short final syllable 'til' made by a consonant, a short vowel, and a consonant (CVC, with $\mathrm{V}$ being short) since its structure is none of those considered long in Tunisian Arabic. Tunisian EFL learners therefore assign stress to the syllable before the last "un" and render an incorrect stress pattern' until instead of un'til.

When it comes to English-French cognates such as restaurant or balance, Tunisian EFL learners tend to apply the French stress rules and assign final stress to these words which should be stressed on the first syllable in English. The study of Ghazali and Bouchhioua (2003) was, however, confined to words the syllable structure of which is similar to Tunisian Arabic or French and would consequently trigger interference from either the mother tongue TA, or from French the L2. Words with a different syllabic structure from TA and which are not at the same time English- 
French cognates were excluded from the study. Consequently, the way this group of learners would handle stress patterns in such words remained unexplored and the possibility that there would be interference from any previously learnt languages needs to be verified.

Because of the importance of correct pronunciation to successful communication and because of the complexity of acquiring an accurate pronunciation of English as L3 by learners from a complex linguistic situation as it is the case for Tunisian EFL learners, the present study has chosen to explore the following research questions:

1) How do Tunisian EFL learners produce the syllables <in, yn, or im> in words like information, syntax, important, the spelling and meaning of which are similar to French?

2) Where would Tunisian EFL learners place lexical stress in English polysyllabic words the syllabic structure of which has no resemblance to either English-French cognates or TA stress patterns?

Literature on third language acquisition and cross-linguistic influence especially in linguistic contexts in which L2 and L3 are typologically similar leads to the following research hypotheses:

1) Tunisian EFL learners are expected to produce the syllables <in, yn, im > in English words like information, syntax, important with the French nasalized vowel $[\tilde{\varepsilon}]$ rather than the English correct pronunciation.

2) Because of the influence of French as L2, Tunisian EFL learners are expected to place stress in English polysyllabic words on the final syllable.

The following section presents the methodology used to test these two research hypotheses.

\section{Methodology}

Test material

\section{The segmental level}

The test material used to investigate transfer of the French nasalized vowels $[\tilde{\varepsilon}]$ with its different spellings into the pronunciation of EnglishFrench cognates such as institution, syntax, information consisted of a short text that was read and then retold by the participants in this study. The text contains 138 words in total. Thirteen of these words are English -French cognates with different spellings of the nasal vowel. These words are "linguistics (3times), important, information, linguist, linguists, individual, institution, interaction, distinctive, principle, syntax". A few basic English words with the grapheme <in> such as " insight, inside, inherent, instead," were included as fillers to verify whether the same pronunciation will also 
occur with these words (see Appendix A).

\section{The suprasegmental level}

The test material used to explore the way Tunisian EFL learners assign stress (as a suprasegmental feature) to English words that are not English-French cognates and have a different syllable structure from Tunisian Arabic consisted of another short passage containing 96 words in total. The target words in this passage were 20 polysyllabic words. Ten out of these twenty words were regular verbs used in the simple past, that is, all ending in the inflectional morpheme <-ed>. The other ten words consisted of nouns and adjectives with various stress patterns (see Appendix B).

\section{Participants}

Thirty Tunisian English- major female students with an intermediate level of English proficiency voluntarily participated in this study ( referred to as Tunisian EFL learners in subsequent sections). They were all third year undergraduate students studying English as a specialty in a well-known Tunisian University. A background questionnaire was used to ensure the homogeneity of this population. They were all about the same age (20-21 years old), educated in Tunisian schools, and from a homogenous social background. They all started learning French at primary school at the age of eight and then learned English at preparatory (middle) school at the age of 12. Care was also taken so that none of these participants had a parent who was not Tunisian. This was meant to reduce the risk of another dialect or another language affecting the participant's speech.

Eight female Tunisian university teachers of English with ages ranging between 32 and 43 also voluntarily participated in the study. A background questionnaire determined that they also had a very similar social background in that they were all educated in Tunisian public schools, graduated from Tunisian public universities, and both of their parents were Tunisians. The only difference was that the two eldest teachers in this group (41 and 43 years old) reported that they started learning French at the age of 9 , that is, one year later than the six other teachers who all studied French at the age of 8. All these teachers, however, learned English at the age of 16 (much later than the group of students). The reason behind including teachers as participants in the study is to see whether the level of proficiency has an effect on the presence/ or absence of the pronunciations of the target features.

\section{Procedure}

To test the research hypotheses, the students were asked to read a short text (one text for each hypothesis: Appendices A and B) and they were recorded individually. They were then asked to retell the content of the text 
using their own words. The aim behind this was to compare the pronunciation of the test items in read speech to spontaneous speech. Before starting the recordings, participants were told to take their time reading the text silently or loudly according to their preferences. When participants felt confident and ready, the recordings started. The recordings took place in a quiet room using Praat; computer software for the acoustic analysis of the speech signal that offers a practical recording option. The recordings were labeled and saved into the computer. They were made over a period of six days, five students each day. The same procedure was followed with the second category of participants, that is, the eight female teachers. All the participants; students and teachers were naïve to the purpose of the experiment.

\section{Results}

The data were subjected to double blind error analysis by two experienced phonetics teachers based on auditory impression. The error analysis consisted of listening carefully to the readings and to the spontaneous speech of each participant individually in order to diagnose the production of the target segments (the pronunciation of the vowel sound in the graphemes $<\mathbf{i n}, \mathbf{y n}, \mathbf{i m}>$ in the target words as well as in the filler words (in text A)) and to detect on which syllable stress was placed by the participants in the target words (text B). The inter-transcriber agreement was about $98 \%$. Statistical tests were then run to check the significance of the results obtained.

\section{The production of the vowel sound in the syllables <in, yn, im $>$ by Tunisian EFL learners}

Interference from French in the pronunciation of the syllables <in, yn, im> in the13 English-French cognates in read speech was checked statistically for significance through a one-tailed Wilcoxen Matched-Pairs Signed -ranks test, which gave a significant value $(\mathrm{T}=31, \mathrm{df}=12 ; \mathrm{p}<.05)$. This significant value shows that Tunisian EFL learners tend to produce French nasalized vowels instead of the correct English vowels while reading an English text containing English-French cognates with the graphemes <in, yn, im>. In fact, words like information and linguistics were pronounced with the French nasalized vowel[$[\tilde{\varepsilon}]$ in $82 \%$ and $79 \%$, respectively. Correct pronunciations and any other type of renditions of the target feature were classified as " other" in the analysis. The same statistical test was run to check whether the same tendency is present in spontaneous speech and the results revealed a higher level of significance $(\mathrm{T}=58, \mathrm{df}=12 ; \mathrm{p}<.05)$. Interference from L2 in the pronunciation of the target segments seemed to 
be higher in spontaneous speech, where less control on one's speech takes place. Figure 1 provides a visual display of this tendency.

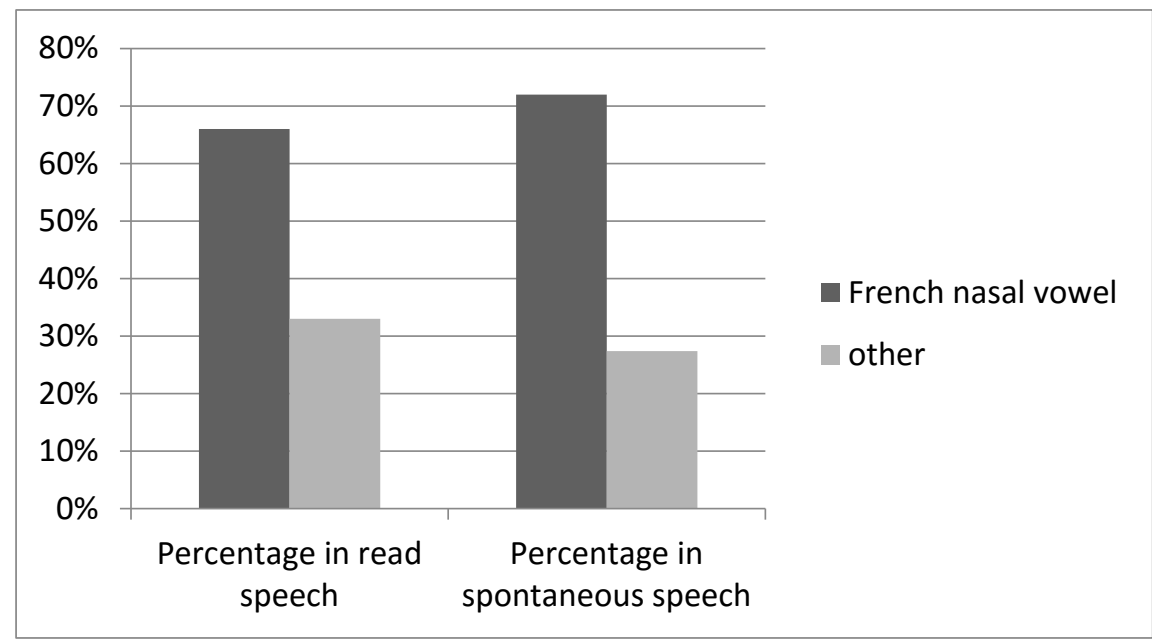

Figure1: Interference from French in the production of the target words in read vs. spontaneous speech by Tunisian EFL learners.

The production of the vowel sound in the syllables <in, yn, im> by Tunisian English language teachers

The same variable was checked through the same statistical test for the population of teachers which comprised 8 participants. As far as read speech is concerned, the one-tailed Wilcoxen test (with $\mathrm{df}=7$ and $\mathrm{p}<.05$ ) provided a non-significant value. However, when the same test was run for spontaneous speech, a significant value was provided $(\mathrm{T}=27, \mathrm{df}=7, \mathrm{p}<.05$. These results show that while teachers control their pronunciation of the target segments in read speech, interference from L2 was unavoidable in spontaneous speech where less control takes place. Table 1 provides means and standard deviations for the production of the target segments by the population of teachers in read speech and spontaneous speech.

Table1: Descriptive statistics of the use of French nasalized vowel in read and spontaneous speech by teachers

French nasalized vowels in read speech

French nasalized vowels in spontaneous

\section{speech}

\section{Number of \\ Mean} observations

84

222
6.6

20.3
Percentage

$31 \%$

$62.5 \%$
Standard deviation 


\section{Word stress placement in polysyllabic English words by Tunisian EFL learners}

Stress placement in the 20 polysyllabic words used in the test was diagnosed and the number of observations where stress was placed on the last syllable (i.e. according to the French stress patterns) was compared to the number of observations where stress was placed elsewhere (whether correctly or incorrectly and which was classified as "other" in the analysis). A one-tailed Wilcoxen Matched-Pairs Signed -ranks test was used to check the significance of the values obtained in read speech first, by the 30 students and verify the hypothesis that the participants would assign French stress to polysyllabic English words. The results were significant $(\mathrm{T}=42, \mathrm{df}=19$; $\mathrm{p}<.05)$. The same test was also run for spontaneous speech and the results were significant as well $(\mathrm{T}=48, \mathrm{df}=19 ; \mathrm{p}<.05)$. Regular past verbs like educated, ignored, and hampered received final stress on <-ed $>$ in more than $60 \%$ of the cases in both read and spontaneous speech. Similar percentages were obtained for the words complexity, assignment, prestigious, which received final stress in more than $59 \%$ of the cases. Table 2 provides means and percentages of the values obtained.

Table 2. Descriptive statistics of the use of French stress patterns in read and spontaneous

\begin{tabular}{|c|c|c|c|c|}
\hline & $\begin{array}{c}\text { French } \\
\text { stress } \\
\text { patterns in } \\
\text { read speech }\end{array}$ & $\begin{array}{l}\text { Other stress } \\
\text { patterns in } \\
\text { read speech }\end{array}$ & $\begin{array}{c}\text { French stress } \\
\text { patterns in } \\
\text { spontaneous } \\
\text { speech }\end{array}$ & $\begin{array}{c}\text { Other stress } \\
\text { patterns in } \\
\text { spontaneous } \\
\text { speech }\end{array}$ \\
\hline $\begin{array}{l}\text { Number of } \\
\text { observations }\end{array}$ & 456 & 89 & 510 & 64 \\
\hline Mean & 26.39 & 8.61 & 28.33 & 10.25 \\
\hline Percentage & $64.88 \%$ & $25.66 \%$ & $66.99 \%$ & $22.89 \%$ \\
\hline
\end{tabular}

Word stress placement in English polysyllabic words by Tunisian English language teachers

To test the hypothesis that Tunisian teachers would assign French stress to polysyllabic English words, a one-tailed Wilcoxen Matched-Pairs Signed -ranks test was used to check the significance of the values obtained in read speech and the results were significant for this population, too $(T=31$, $\mathrm{df}=19 ; \mathrm{p}<.05)$. Then, the same test was also run for spontaneous speech and the results were significant as well ( $\mathrm{T}=34, \mathrm{df}=19 ; \mathrm{p}<.05)$, but slightly higher than in read speech. Figure 2 provides a visual display of the results. 


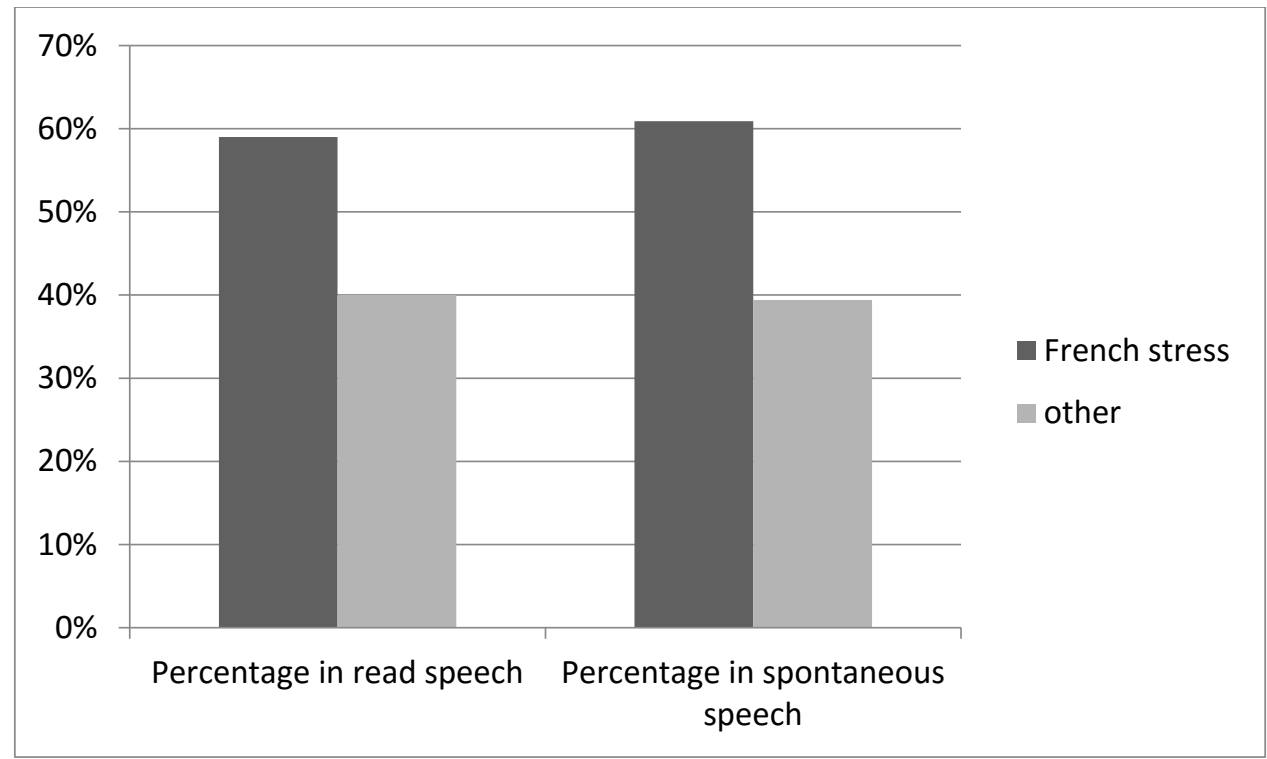

Figure 2. Stress placement in English polysyllabic words by Tunisian English language teachers.

A discussion of the results and their significance is presented in the following section.

\section{Discussion}

The study aimed at checking the effects of French as the second language (L2) learnt by Tunisian students on their learning of English as a third language (L3). Whether the second language has a facilitating or impeding effect remained a controversial matter in similar studies. The present study would, hopefully, contribute to clarifying this issue and providing more insight into it.

The results of the first research question showed that Tunisian EFL learners have the tendency to produce the French nasalized vowel $[\tilde{\varepsilon}]$ in English-French cognates such as information, syntax, linguistics both in read as well as in spontaneous speech, which shows the influence of French on the pronunciation of English. Because of the semantic and orthographic similarity between these words in French and English, the Tunisian EFL learner who has learned French before English tends to transfer the French pronunciation of the graphemes $<\mathbf{i n}, \mathbf{y n}, \mathbf{i m}>$ presented to him in the test and renders them with a French nasalized vowel instead of the correct pronunciation. The second language, here, appears to have a negative rather than a facilitating effect on the leaner's pronunciation of L3. According to Kellerman (1979), transfer is likely to take place when the perceived similarity between the two languages is great and when the structures 
involved are unmarked. The great similarity between French-English cognate vocabulary items such as "information", semantically and orthographically, leads Tunisian EFL learners to unconsciously decide that their pronunciation is similar, too, and therefore produce a French nasal vowel instead. What reinforces the claim that the main factor behind these productions is interference from French is that the pronunciation of the filler test words "insight, inherent, inside, into", which are Basic English words with no resemblance to French, was different. Only in 5\% of the cases were these words produced with the French nasalized vowel $[\tilde{\varepsilon}]$. Although the factor cognate vs. basic English vocabulary was unfortunately excluded from the analysis because of their unequal number in the text used, descriptive statistics clearly demonstrated this tendency. The occurrence of this pronunciation error in both read and spontaneous speech shows that learners have not accurately perceived the difference between the French and the English pronunciations of such segments and have consequently failed to produce them. Correct perception is, in fact, an essential step that leads to accurate and intelligible production.

Despite the fact that teachers did not produce statistically significant French renditions of the target segments in read speech, these French-colored pronunciations existed (as seen during the error analysis) in read speech and reappeared much more significantly in spontaneous speech where the statistical test provided a significant critical value. Tunisian teachers seem to be aware of the difference between French and English in the pronunciation of the target words and were able to produce them in careful read speech. However, in spontaneous speech, where less control takes places on accuracy and the focus of the speaker is rather shifted to meaning and structure, these errors floated significantly on the surface. The classroom interaction between teachers and students happens generally through spontaneous rather than careful speech. In their English classes, teachers explain vocabulary items, grammatical structures, or subject content matter to their students and their focus is therefore shifted from pronunciation to meaning while speaking. The difference in proficiency level between English language teachers and their students seems to have no importance since the same errors were produced in spontaneous speech by the two categories of participants. These learners seem to have acquired a meager and an erroneous pronunciation input from their teachers and therefore reproduced it as such.

This does not only occur at the segmental level (consonants and vowels), but also at the suprasegmental level as demonstrated by the results of the present study. In fact, the second research question aimed at checking the existence of transfer from French in the assignment of stress to English words the syllabic structure of which is different from both the native 
language of the subjects (Tunisian Arabic) and from French as their L2. Transfer from French was hypothesized to happen if participants assigned stress to the last syllable in the test items (i.e. according to the French stress rules). As far as the population of students was concerned, the results showed that Tunisian EFL learners tend to apply French stress rules to English words since they place stress on the last syllable of these words (where it should be placed elsewhere according to English stress patterns) most of the time. Regular past verbs like educated and hampered and other English nouns and adjectives such as complexity, assignment, and prestigious received final stress on almost $60 \%$ of the cases in both read and spontaneous speech. These percentages in addition to the significant values of the statistical test are striking because explaining the cognitive process lying behind this tendency is not an easy matter. Ghazali and Bouchhioua (2003) showed that Tunisian EFL learners tend to apply the stress rules of their native language (TA) when they assign stress to basic English words such as until or upset that are produced with as initial stress instead of the correct final stress in English and that they apply the French stress rules when they pronounce English-French cognates such as restaurant or passport. The cognitive process applied by this group of learners was related to interference from the mother tongue in the first category of words, and to interference from L2 in the second category of words. In this study, a third category of test items was used. It consisted of polysyllabic English words, with a syllable structure that is different from both the mother tongue and L2. Because of the typological difference between the native language of the learners and English as the target language and because of the difference of the syllabic structure of the test items in the two languages, it was expected that the participants would resort to French stress rules and apply them to the test items. Despite the fact that the test items were not English-French cognates and have a high frequency level, interference from French was proved to be significant as the participants resorted to their L2 to compensate for the gap existing in their knowledge of English stress patterns (not knowing on which syllable exactly stress occurs in these English words). The typological similarity between French and English and the whole experience of learning French before English led to interference from L2 to L3 in the phonological acquisition of lexical stress by Tunisian EFL learners in this study.

This tendency was also present in both read and spontaneous speech of the second category of participants who are English teachers as demonstrated by the significant statistical tests used in the study. Though the significance level of the test in spontaneous speech was higher than in read speech, the difference was not great $(\mathrm{T}=34$ in spontaneous speech, $\mathrm{T}=31$ in read speech). This shows that unlike segmental errors (the nasalized vowel 
segment $[\tilde{\varepsilon}])$ that can be more controlled in read speech than in spontaneous speech, word stress errors are unlikely to be subject to speaking style or speed. Actually, the stress of a single word in English is part of its identity and has to be acquired simultaneously with its meaning and syntactic category. Although teachers have a higher proficiency level in English and despite the fact that the target words were all high frequency words, Tunisian teachers seem also to resort French in assigning stress to English polysyllabic words, especially regular past verbs such as educated, disliked and their behavior was very similar to that of students. Although the test items were included as one single variable (without any attributes such syntactic category of the word: verbs, nouns, adjectives) in the statistical analysis, the error analysis revealed that teachers made less errors in stress assignment to nouns or adjectives than to regular past verbs. The lack of mastery of the pronunciation of this important suprasegmental feature "word stress" by the teachers and their tendency to resort to the previously learnt language (French) rules seems to have been transferred to their students, who in turn produced wrong renditions of English word stress.

According to Ringbom, (1987), transfer is more likely to happen from the first language than from later-learned languages. However, the present study shows that typological similarity between the languages involved seems to have a stronger effect. The findings of this study are, thus, in conformity with previous research evidence such as Möhle (1989), Singleton (1987), and Cenoz (1998) that proved cross-linguistic transfer in multilingual acquisition, especially when the languages involved are similar in many aspects. The transfer theory has been criticized and rejected in many fields of second language learning. However, at pronunciation level, its role has always been recognized especially in accounting for foreign accent and in relation to the acquisition of some segments and suprasegmental features of the target language (Celce-Murcia, Brinston \& Goodwin, 1996).

Acquiring English as a third language is different from and much more complex than acquiring it as a second language. Therefore, practical implications such as the best age for introducing different languages as well as the desired level of proficiency in each need to be carefully planned. In addition, the socio-cultural context in which languages are learned needs to be taken into consideration because research evidence such as Safont (2005) and the present study show that it does affect the acquisition of a third language. Since in most multicultural societies languages have different status and roles and are used for different functional purposes as it is the case in the Tunisian educational context, designing special language teaching programs with specific foci that address the potential difficulties of a group of learners and provide the right remedy for them, especially in 
pronunciation teaching, has now become a necessity.

\section{Conclusion}

This study was designed to check the effects that French (as L2) has on the acquisition of English pronunciation (as L3) in the Tunisian educational context that is characterized by a complex linguistic situation. Results show significant interference from French in the pronunciation of English by both Tunisian EFL learners and their teachers. The typological similarity between French and English, the important number of cognate vocabulary they share, and their similar orthography makes Tunisian learners resort to French and apply its pronunciation features while producing English speech. More information and more precise results could, however, have been obtained if other variables such as the syntactic category of the words used were tested and if the size of the population was larger. These results, yet, can be useful to English language teachers, material designers, and applied linguists since educational programs and specific syllabi (such as a pronunciation syllabus) should be based on the nature of the sociolinguistic situation of each country, account for the possible factors that intervene with the process of acquisition, and should promote multicultural acquisition. Because acquiring English as a second language has been fairly enough searched and because multilingualism is growing and becoming a characteristic feature of many societies in the world, future research should be directed more to third language acquisition, especially spoken language acquisition with all its aspects in multicultural contexts.

\section{References:}

Anderson, R. (1983). Transfer to somewhere. In S. Gass \& L. Selinker (Eds.). Language transfer in language learning (pp. 177-201). Rowley, MA: Newbury House

Battye, A. \& Hintze, M.A. (1992). The French language today. London: Routledge.

Celce-Murcia, N., Brinton, M.D., \& Goodwin, J.M. (1996). Teaching pronunciation: A reference for teachers of English to speakers of other languages. Cambridge: Cambridge University Press

Cenoz, J., \& Genesee, F. (Eds.). (1998). Beyond bilingualism: Multilingualism and multilingual education. Clevedon, England: Multilingual Matters

Cenoz, J. (2001). The effect of linguistic distance, L2 status and age on cross-linguistic influence in third language acquisition. In J. Cenoz, B. Hufeisen, \& U. Jessner (Eds.). Crosslinguistic influence in third language acquisition: Psycholinguistic perspectives 820).Clevedon, UK: Multilingual Matters 
Cenoz, J. (2003). The additive effect of bilingualism on third language acquisition: A review. The International Journal of Bilingualism 7, 71-89.

Cenoz, J. \& Jessner,U.(2000). English in Europe. The acquisition of a Third Language. Clevedon: Multilingual Matters

Cenoz, J. \& Hoffmann, C. (2003). Acquiring a third language: what role does bilingualism play? International language of Bilingualism 7 (1): 1-6

Clyne, M. 1997. Some of the things trilinguals do. International Journal of Bilingualism 1, 95-116.

Derwing, T. M., Munro, M. J., \& Wiebe, G. E. (1998). Evidence in favor of a broad framework for pronunciation instruction. Language Learning, 48, 393410.

Hanafi, A. (2014). The second language influence on foreign language learners' errors: the case of the French language for Algerian students learning English as a foreign language. European Scientific Journal (2), pp.32-38.

Ghazali, S. (1973). Tunisian Arabic and French phonological interference: stress and the phoneme/h/. Unpublished MA Dissertation. University of Texas.

Ghazali, S. \& Bouchioua, N. (2003). The learning of English prosodic structures by speakers of Tunisian Arabic. Proceedings of the $13^{\text {th }}$ International Congress of Phonetic Science, Barcelona.

Kellerman, E. (1979). Transfer and non-transfer: where are we now? Studies in Second Language Acquisition, 2 (1), pp.37-57.

Kellerman, E. (1983). Now you see it, now you don't. In S. Gass \& L. Selinker (Eds.)

Language transfer in language learning (pp.112-134). Rowley, MA: Newbury House.

Kellerman, E. (1986). An eye for an eye: Crosslinguistic constraints on the development of the L2 lexicon. In M. Sharwood Smith \& E. Kellerman (Eds.), Crosslinguistic influence in second language acquisition (pp. 35-48). Oxford, UK: Pergamon Press.

Kellerman, E. (1995). Crosslinguistic influence: Transfer to nowhere? Annual Review of Applied Linguistics, 15, 125-150.

Negadi, M. (2015). Learning English in Algeria through French-based background proficiency. Procedia- Social and Behavioral Sciences (99), pp 496-500.

Möhle, D. (1989). Multilingual interaction in foreign language production. In H.W. Dechert and M. raupach (eds). Interlingual Processes (pp.174-94). Tübingen: Gunter Narr.

Murphy, Sh. (2003). Second language transfer during third language acquisition. Working Papers in TESOL \& Applied Linguistics, journal.tclibrary.org 
Odlin, T. (1979). Language Transfer: cross-linguistic influence in language learning. Cambridge: Cambridge University Press.

Ringbom, H. (1987). The role of the First Language in Foreign Language Learning. Clevedon: Multilingual Matters.

Safont, M. P. (2005). Third Language Learners. Second Language Acquisition. In Singleton, D (Ed). Clevedon: Multilingual Matters.

Singleton, D. (1989). Language acquisition: The age factor. Clevedon. Multilingual Matters.

Sharwood Smith, M., \& Kellerman, E.(1986). Crosslinguistic influence in second language

acquisition: An introduction. In M. Sharwood Smith \& E. Kellerman (Eds.), Cross-linguistic influence in second language acquisition (pp. 1-9). Oxford, UK: Pergamon Press

\section{Appendix A \\ Text 1}

Linguistics is the scientific study of language. It provides important information about how speech is stored inside our minds and how it is generated phonetically. Linguists are primarily concerned with natural languages and instead of imposing rules on speakers; they just describe what people use. The linguist wants to know whether all languages have something in common. Linguistics looks also at the inherent properties of language. Hall (1968) tells us that language is "the institution whereby humans communicate and interact" The terms communication and interaction are used here because they are among the most distinctive properties of human language. Some linguists are concerned with the individual differences between speakers of the same language and seek to provide insight into this issue. The principle that governs linguistic research is objectivity. Branches of linguistics comprise semantics, syntax, morphology and phonology.

\section{Appendix B}

Text 2

Kelly is a pretty girl who was educated in luxurious prestigious high school. The girl worked hard, planned her daily activities, and noted down all details on her note book. She searched for information everywhere and never ignored the complexity of her work. Her favorite subject was economics and she enjoyed studying it. She was, however, hampered by the successive assignment her English teacher gave them. These assignments took all her time and energy and deprived her from investing more efforts on her best subject. She disliked her English teacher and thought she was really boring. 